Journal of Engineering and Applied Sciences 7 (3): 271-278, 2012

ISSN: 1816-949X

(C) Medwell Journals, 2012

\title{
Design of Passive Filters for Industry Applications Using Genetic-Algorithm and Particle Swarm Optimization
}

\author{
Sreenivasulu Yaparala and M. Kowsalya \\ School of Electrical Engineering, Power Electronics and Drives Division, \\ VIT University, Vellore, Tamil Nadu, India
}

\begin{abstract}
Due to the increase in non-linear loads, power lines have become highly polluted. Passive filters have been used near harmonic-producing loads or at the point of common coupling to mitigate the current harmonics. For industries, having large number of variable frequency drives power fed through power cable reduces the reactive power requirement in the power system. Under such reduced reactive power requirement, the design of passive filter conforming to the IEEE 1531 standard is presented in this study. The objective is to propose a new approach for designing the tuned harmonic filters by using Genetic Algorithm (GA) and Particle Swarm Optimization (PSO). The main goal in projecting the harmonic filters is to minimize the net source RMS current. The optimal parameters obtained through GA and PSO are used to design the passive filter parameters. The performance and operation of the so-designed passive filter has been studied through simulation under Matlab environment.
\end{abstract}

Key words: Variable frequency drives, passive filters, harmonic mitigation, genetic algorithm, particle swarm optimization, India

\section{INTRODUCTION}

Power system harmonics are a menace to electric power system with sudden consequences. A number of ways were tried out to tackle the harmonic problem posed by non-linear electric devices. The line current harmonics cause increase in losses, instability and also voltage distortion when these harmonics travel upstream and produce drop across line impedance (Nelson, 2004). Situation becomes more critical when the power system is for petroleum field where the stiffness in the supply is never achieved (Nelson, 2004; Petro and Wood, 1994; Merhej and Nichols, 1992). A number of ways were tried out to tackle the harmonic problem posed by non-linear electric devices but by far, the most popular and quiet effective one is the use of passive filters. Passive filters designed by different constraints have been reported and tried to compensate the harmonics produced by non-linear loads along with reactive power compensation.

Passive filters remained popular and effective for petroleum field due to their low cost, rugged structure and higher efficiency (Berizzi and Bovo, 2000). As reported in literature, passive filters are designed to incorporate harmonic compensation and reactive power minimization (Merhej and Nichols, 1992; IEEE, 2003; Wakileh, 2001; Das, 2004; Upadhyaya and Atre, 1998; Lin et al., 1998;
Haozhong et al., 1995; Kawann and Emanuel, 1996). Passive filters designed for consideration to minimize reactive power are actually not a major constraint for petroleum field as the power cable used for power transmission in petroleum field offers a capacitive reactance (Merhej and Nichols, 1992). This additional capacitive reactive power mitigates the lagging reactive power requirement offered by thyristorized $\mathrm{DC}$ and $\mathrm{AC}$ drives, transformers and other loads of similar type.

Some schemes have reported that passive filters operate such that damping and attenuation of harmonics which are amplified due to series and parallel resonances (occurring between the line and capacitive impedances of passive filters or capacitive impedance of the submerged cable and inductive impedance of transformer and inductance of passive filters) can be achieved. Majority of applications at petrochemical industries demand variable speed operation of motors. Thus, Variable Frequency Drives (VFDs) have replaced the previously existing conventional drives (Nelson, 2004; Petro and Wood, 1994; Merhej and Nichols, 1992). These VFDs have high displacement factor and the requirement of lagging reactive power by other thyristorized drives may be fully quenched by the leading reactive power provided by the power cable for power transmission to the petroleum system (Merhej and Nichols, 1992). Therefore, the

Corresponding Author: Sreenivasulu Yaparala, School of Elecrical Engineering, Power Electronics and Drives Division, VIT University, Vellore, Tamil Nadu, India 
additional capacitive reactance offered by passive filters forces the system to draw more current from generator units. This capacitive current creates problems of voltage regulation in the power system.

In addition to this, the increased RMS current increases losses and stops the system. Therefore, there is a need to change the design parameter of passive filters used for petroleum power systems. Such a design needs to minimize the additional capacitive reactance by forcing the system to have minimum RMS current as design parameter. To avoid the problem of resonance, the design of passive filters has to be done for dedicated application with the VFD unit which gets switched off along with the drive (Petro and Wood, 1994; IEEE, 2003). The design of such passive filter has to be done by optimizing the value of capacitance in the passive filter so that the criterion of minimum RMS line current is achieved. Thus, minimization of harmonics and supply RMS current has been adopted as the design parameters for passive filters designed for dedicated applications with VFDs in accordance with IEEE-15 (IEEE, 2003). The traditional optimization methods may undergo a step-by-step searching algorithm which locates the local optima whereas Genetic Algorithms (GAs) and PSO with the ability of parallel searching through the entire solution space can give global optima (Moura et al., 2002; Chen, 2003; Berizzi and Bovo, 2000; Goldberg, 1989; Chipperfield et al., 1994; Sarangi, 2009).

By using GAs and PSO, designers can quickly find appropriate parameter values to meet the desired passive filter performance as it reduces the number of calculations in comparison to the existing methods. At the same time, GAs and PSO are able to handle many constraints simultaneously which are not done at ease with other reported algorithms (Moura et al., 2002; Goldberg, 1989; Chipperfield et al., 1994). The objective of this study is to propose a new approach for passive filter design particularly for industries having a large number of VFDs. A new design methodology using GAs and PSO is proposed in this study which can give a near-optimum solution. The optimization process is based on the design of the passive filter for minimization of harmonic contents and RMS line current simultaneously. The proposed design is simulated under the Matlab software. Simulation results show that the filter designed by the proposed GAs and $\mathrm{PSO}$ can meet the desired power quality requirement.

\section{PROBLEM FORMULATION}

The objective is to find an optimal selection of components of passive filter connected to each VFD shown in Fig. 1. The configuration enables the system to

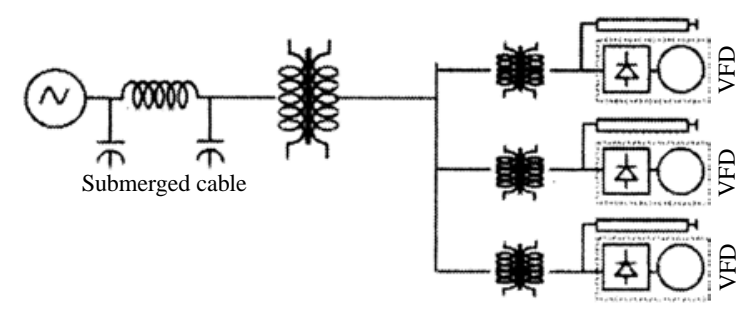

Fig. 1: System configuration

reduce net voltage distortion at the $\mathrm{PCC}$ due to a very low impedance path provided by these harmonic filters. The design has been carried out by GA and PSO which optimizes the solution for many variables.

System configuration: The filter harmonic admittance (per unit) for a 1st order series single tuned filter is represented as follows (Wakileh, 2001):

$$
\mathrm{Y}_{\mathrm{Fmh}}=\sum_{\mathrm{n}=5,7} \frac{\mathrm{Q}_{\mathrm{Fh}}}{\mathrm{V}^{2}}\left[\frac{\mathrm{h}\left(\mathrm{n}_{\mathrm{h}}^{2}-1\right)}{\mathrm{h}^{2}-\mathrm{n}_{\mathrm{h}}^{2}}\right]
$$

Where:

$\mathrm{Q}_{\mathrm{Fh}}=$ The filter capacity

$\mathrm{h}=$ The harmonic index

$\mathrm{n}_{\mathrm{h}}=$ The resonant point

The filter admittance (per unit) for a 2nd order High Pass Filter (HPF) with corner frequency can be represented as (Wakileh, 2001):

$$
\mathrm{Y}_{\mathrm{F} 1 \mathrm{~h}}^{\prime}=\frac{1}{\left[\frac{\mathrm{hR} \mathrm{R}_{11}^{2} \mathrm{X}_{\mathrm{L}}}{\mathrm{R}_{11}^{2}+\left(\mathrm{hX} \mathrm{X}_{\mathrm{L}}\right)^{2}}-\frac{\mathrm{X}_{\mathrm{L}}}{\mathrm{h}}\right]}
$$

Where:

$$
\begin{gathered}
X_{C}=\frac{V^{2} n_{h}^{2}}{Q_{F 11 h\left(n_{h}^{2}-1\right)}} \\
X_{L}=\frac{X_{C}}{n_{h}^{2}}
\end{gathered}
$$

Therefore, the net admittance offered by a filter bank consisting of series tuned filters at resonant points $n_{5}$ and $\mathrm{n}_{7}$, together with $2 \mathrm{nd}$ order damped HPF is given by:

$$
\mathrm{Y}_{\mathrm{Fmh}}^{11}=\mathrm{Y}_{\mathrm{Fmh}}+\mathrm{Y}_{\mathrm{F} 11 \mathrm{~h}}^{\prime}
$$

The equivalent source admittance $Y_{\text {sh }}$ shown in Fig. 2 corresponds to the admittance offered by the source, the cable and the transformers in the line. $I_{h}$ 


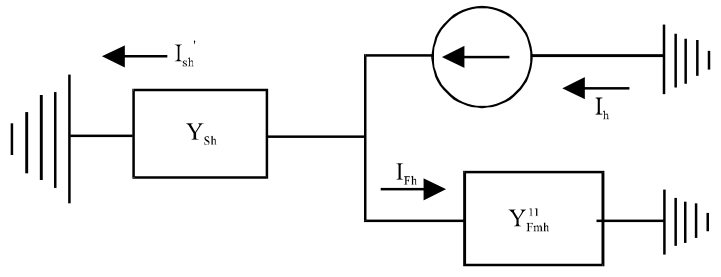

Fig. 2: Equivalent circuit for any hth order harmonic distortion where $h=5,7, \ldots$

represents the current at hth harmonic frequency from the load which is acting as a harmonic current source in the aforementioned equivalent circuit. $I_{\mathrm{Fh}}$ represents the harmonic current for which the passive filters are designed during test conditions and $I_{\text {sh }}$ represents the harmonic current data corresponding to source current during test conditions. Therefore, the harmonic current $I_{\text {sh }}$ escaping to the source side at the PCC can be represented as:

$$
I_{\text {sh }}^{\prime}=I_{s h} \times\left(\frac{I_{h}}{I_{h h}}\right)
$$

Equation 4 can be further being expressed in a more generalized form that is valid for any number of filters by the equation:

$$
I_{s h}^{\prime}=\frac{Y_{s h} \times I_{h}}{Y_{s h}+Y_{F m h}^{\prime \prime}}
$$

The main idea is to minimize $\mathrm{I}_{\mathrm{sh}}$ which is subjected to the system variables.

System variables: With the minimization of net harmonic current flow toward the source side, determined by minimizing the harmonic filter impedance as compared to the source impedance and maximizing the filter impedance at fundamental frequency, the addition of a passive filter would result in the net RMS current reduction, due to more reduction in harmonic current contents in the source currents than an increase of fundamental frequency current sinking in the passive filters.

Minimizing harmonic source current: The harmonic current minimization is the prime objective of the algorithm. The minimization of harmonic current has been ensured by minimizing the net harmonic current contents in the source current. This can be represented by a summation of all harmonic current contents at different harmonic frequencies as:

$$
\mathrm{I}_{\mathrm{h}}^{\prime}=\sqrt{\sum_{\mathrm{h}=5,7, \ldots}\left(\mathrm{I}_{\mathrm{sh}}^{\mathrm{i}}\right)^{2}}
$$

Minimizing fundamental current in passive filters: The constraint of maximizing the passive filter impedance at fundamental frequency is given:

$$
\operatorname{Max}\left[\frac{\left|Z_{1}\right|}{\gamma}\right] \text { or } \operatorname{Min}\left[\gamma \cdot \frac{1}{\left|Z_{1}\right|}\right]
$$

Reactive power: The other operational constraint is to accumulate a reserve of reactive power for stable operation of the power system. The summation of the filter's reactive power has been kept equal or less than the total reactive power compensation required for the system:

$$
\sum_{m=5,7,11, \ldots} Q_{\mathrm{Fm}}=\mathrm{Q}_{\mathrm{c}}
$$

where, $m$ denotes the filter legs tuned at resonant points.

Environment conditions: The environment conditions play an important role in the determination of the smooth operation of filters while in operation. It therefore becomes mandatory to evaluate the passive filter performance due to changes in environment conditions before installation of filters as per IEEE 1531 standard (IEEE, 2003). The study deals with the evaluation of the design under changes in frequency, capacitance and inductance of the filter banks. Frequency variation in power system is reported to be about $\pm 1 \%$ (Lin et al., 1998):

$$
-1 \%<\frac{\Delta \mathrm{f}}{\mathrm{f}}<+1 \%
$$

The capacitors change their values due to temperature and tolerance specified by the manufacturing process. It has a $\pm 2 \%$ error due to the change of temperature and $0 \sim+10 \%$ errors due to manufactures. Therefore, the total errors that can be incorporated against manufacture can be given for capacitance as (IEEE, 2003):

$$
-2 \%<\frac{\Delta \mathrm{C}}{\mathrm{C}}<+2 \%
$$

and for inductance is:

$$
-2 \%<\frac{\Delta \mathrm{L}}{\mathrm{L}}<+2 \%
$$




\section{J. Eng. Applied Sci., 7 (3): 271-278, 2012}

The common resonant point of the filter bank unit consisting of series tuned filter of 5 th and 7 th harmonic frequencies and $\mathrm{HPF}$ at 11 th harmonic frequency corner frequency is given by:

$$
\mathrm{n}_{\mathrm{h}}=\frac{1}{2 \pi \mathrm{f} \sqrt{\mathrm{LC}}}
$$

From the aforementioned considerations, the possible region of variation of the common resonant point $\mathrm{n}_{\mathrm{h}}$ can be expressed as:

$$
\begin{aligned}
\frac{\mathrm{h}}{1.01 \times \sqrt{1.03 \times 1.12}}<\mathrm{n}_{\mathrm{h}} & <\frac{\mathrm{h}}{0.99 \times \sqrt{0.97 \times 0.98}} \\
0.92 \mathrm{~h} & <\mathrm{n}_{\mathrm{h}}<1.036 \mathrm{~h}
\end{aligned}
$$

For $\mathrm{h}=5$, the variation of the resonant point would be defined between $4.60<n_{h}<5.18$. The variation in the resonant point indicates the range within which harmonic over load of filter is possible due to series resonance. It means that to design a filter suppressing the 5th-order harmonic, a compromise has to be made on detuning the filter to avoid series resonance due to distorted mains.

\section{GENETIC ALGORITHM}

GAs are efficient tools to solve optimization problems, based on the principle of natural selection and genetically developed off springs (Berizzi and Bovo, 2000; Chipperfield et al., 1994). The optimization procedure follows an evolutionary strategy to find the best solution of a search problem. Thus, starting from an initial population of individuals, each one representing a possible solution, the evolution takes place and changes the population to form the next generation until a convergence criterion is fulfilled.

At this point, the solution is given by the best individual. Each individual is represented by a chromosome (string) which holds all the information on the control variables associated to the point in the search space represented by that individual; generally, the control variables are coded using a binary conversion. The optimization process tries to optimize an each individual a fitness value strictly related with that function; the fitness function must always be maximized during the evolution.

The process begins with the choice random or guided by heuristics of a starting population. It is important that this population holds a high variety of chromosomes, since diversity is one of the most powerful tools of GAs. The more diverse each generation is the more efficient the search of the best solution is as the GA intrinsic parallelism is fully exploited. A classical GA proceeds using the following three operators:

Selection: Some individuals are selected in order to mate and to pass their genetic code to the next generation. The choice of these individuals is made randomly but the probability of an individual to be selected is proportional either to its fitness or to its position in a merit order. The most promising solutions have great probability to survive but other solutions are not necessarily rejected (they could still hold useful information).

Crossover: Each couple of selected individuals (parents) can experience the crossover with a probability $\mathrm{Pc}$ (typically, $\mathrm{Pc}=0.6-0.9$ ) defined by the user. In the simplest form, a cut point is randomly chosen in the selected individuals and the two couples of substrings are swapped.

Mutation: Each bit of a chromosome can be modified (from $0-1$ or vice versa) with a very low probability $\mathrm{Pm}$ $(\mathrm{Pm}=0.001-0.01)$ set by the user. This introduces new features in the next generation and allows the GA search capability to be increased.

\section{PARTICLE SWARM OPTIMIZATION}

Particle Swarm Optimization (PSO) is a population based Stochastic Optimization Technique, inspired by social behavior of bird flocking or fish schooling. PSO shares many similarities with Evolutionary Computation Techniques such as Genetic Algorithms (GA). The system is initialized with a population of random solutions and searches for optima by updating generations. However, unlike GA, PSO has no evolution operators such as crossover and mutation.

In $\mathrm{PSO}$, the potential solutions called particles, fly through the problem space by following the current optimum particles. The advantages of PSO is easy to implement and there are few parameters to adjust (Sarangi, 2009). PSO has been successfully applied in many areas: function optimization, artificial neural network training, fuzzy system control and other areas where GA can be applied.

PSO is initialized with a group of random particles (solutions) and then searches for optima by updating generations. In every iteration, each particle is updated by 
following two best values. The first one is the best solution (fitness) it has achieved so far (The fitness value is also stored). This value is called pbest. Another best value that is tracked by the particle swarm optimizer is the best value, obtained so far by any particle in the population.

This best value is a global best and called gbest. When a particle takes part of the population as its topological neighbors, the best value is a local best and is called pbest. After finding the two best values, the particle updates its velocity and positions with following equation (Sarangi, 2009):

$$
\begin{gathered}
\mathrm{V}_{\mathrm{i}}^{(\mathrm{u}+1)}=\mathrm{W} * \mathrm{~V}_{\mathrm{i}}^{(\mathrm{u})}+\mathrm{C}_{1} * \operatorname{rand}() *\left(\text { pbest }-\mathrm{P}_{\mathrm{i}}^{(\mathrm{u})}\right)+ \\
\mathrm{C}_{2} * \operatorname{rand}() *\left(\text { gbest }-\mathrm{P}_{\mathrm{i}}^{(\mathrm{u})}\right) \\
\mathrm{P}_{\mathrm{i}}^{(\mathrm{u}+1)}=\mathrm{P}_{\mathrm{i}}^{(\mathrm{u})}+\mathrm{V}_{\mathrm{i}}^{(\mathrm{u}+1)}
\end{gathered}
$$

Objective function for GA and PSO: Incorporating the main objective, i.e., minimization of harmonic currents in mains along with the system constraints of maximizing the filter impedance at fundamental frequency and net reactive power requirement, constitutes the objective function as:

$$
\mathrm{Obj} F=\sqrt{\sum_{\mathrm{h}=5,7,11}\left(\mathrm{I}_{\mathrm{sh}}^{1}+\alpha \mathrm{P}_{1}+\beta \mathrm{P}_{2}\right)^{2}}
$$

Where:

$$
\begin{gathered}
\mathrm{P}_{1}=\left[\gamma \cdot \frac{1}{\left|\mathrm{z}_{1}\right|}\right] \\
\mathrm{P}_{2}=\left(\mathrm{Q}-\sum_{\mathrm{m}=5,7,11 \ldots \ldots} \mathrm{Q}_{\mathrm{Fm}}\right)^{2}
\end{gathered}
$$
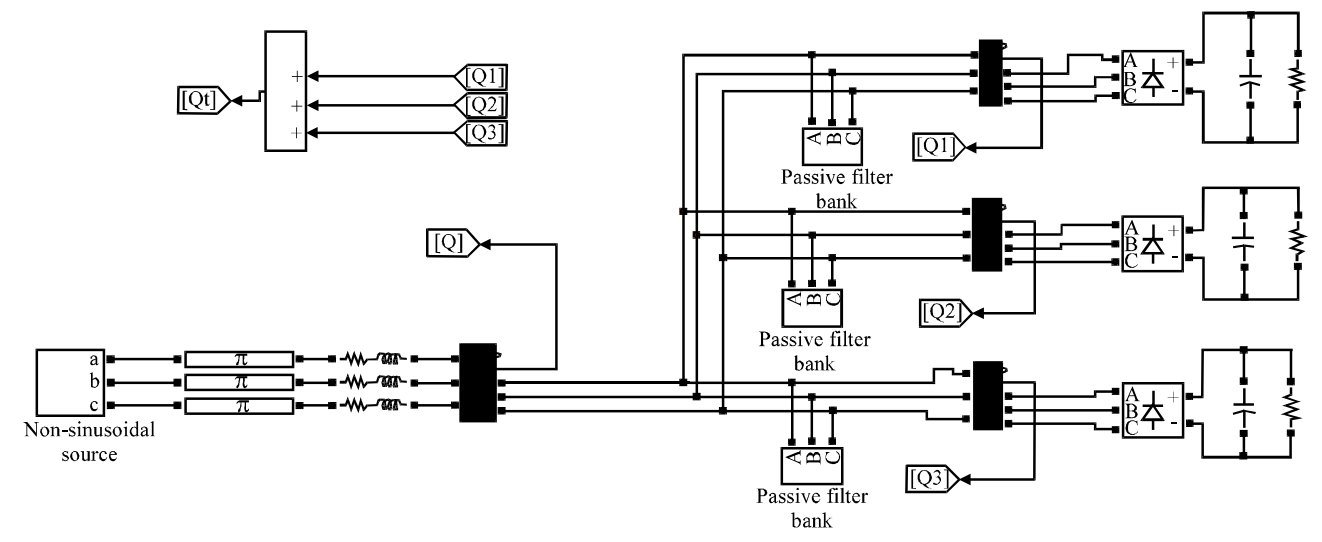

Fig. 3: Matlab block diagram consisting of power system and VFD loads for passive filters represents the penalty functions $\mathrm{P}_{1}$ and $\mathrm{P}_{2}$ for maximization minimization of constraints described by Kawann and Emanuel (1996) and Moura et al. (2002). The values of these penalty functions depend upon the degree to which constraints are violated. $\alpha$ and $\beta$, the multiplication constants which will control the influence of the penalty functions over the objective function optimize the design against major constraints for smoother operation of passive filters. The optimization of parametric values thus meets the prime objectives in addition to near-amicable conformity with other two constraints which enhances the performance of the design. The steps in algorithm can be followed (Verma and Singh, 2010).

\section{MATLAB BASED SIMULATION}

The power source including cable, transformer, VFDs and passive filter bank is modeled in Matlab using the Power System Blockset. Figure 3 shows the test bench to estimate the performance of the passive filters under equivalent offshore power system conditions though Matlab simulation. The source block consists of a 3-phase power source with $\Pi$ section cable and transformer that produce finite impedance making the source non-stiff. The performance of the designed set of passive filters with the aforementioned placement has been studied. The set of passive filters includes bank of passive filters consisting of tuned passive filter at the 5th and 7 th harmonic frequencies and a 2nd-order damped HPF whose corner frequency is kept at 11th harmonic frequency as per IEEE 1531 standard. The VFD has been modeled with a diode rectifier with a smoothing capacitance of $200 \mu \mathrm{F}$ and an $\mathrm{AC}$ drive as equivalent resistance which represents the real power consumed by the load. This equivalent resistance corresponds to a $9.25 \mathrm{~kW}$ drive. 


\section{DISCUSSION}

Figure 4 and 5 shows the THD and RMS values of voltage and current without passive filters for sinusoidal source. And similarly Fig. 6 and 7 shows the THD and RMS values of voltage and current without passive filters for non-sinusoidal source. Figure 8 and 9 shows the source current (IS) and line voltage at PCC $\left(\mathrm{V}_{\mathrm{pcc}}\right)$ for Dedicated Passive Filter (DPF) for each VFD using GA and PSO. It is clearly shown in Fig. 10 and 11 that the power system is very weak. Even with very low harmonic contents in the source current, the voltage waveform is highly distorted at PCC. With the application of passive filters, the THD of the source current under such condition has been improved from $18.69-2.97 \%$ using GA

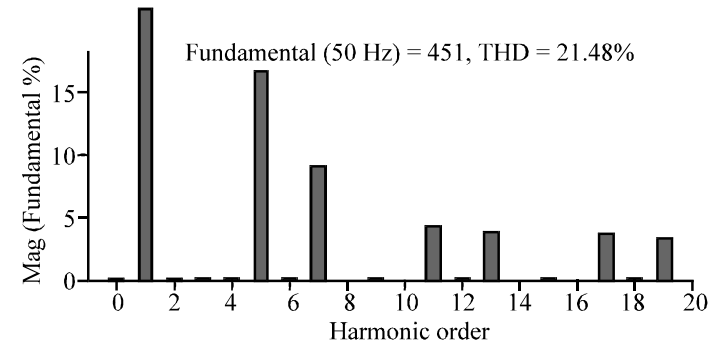

Fig. 4: THD and RMS values of voltage without PF for sinusoidal source

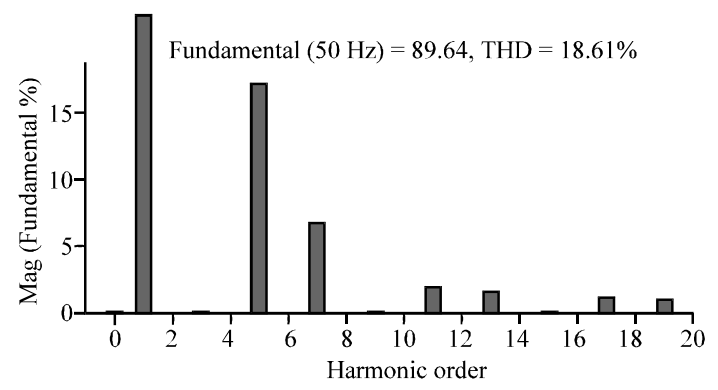

Fig. 5: THD and RMS values of current without PF for sinusoidal source

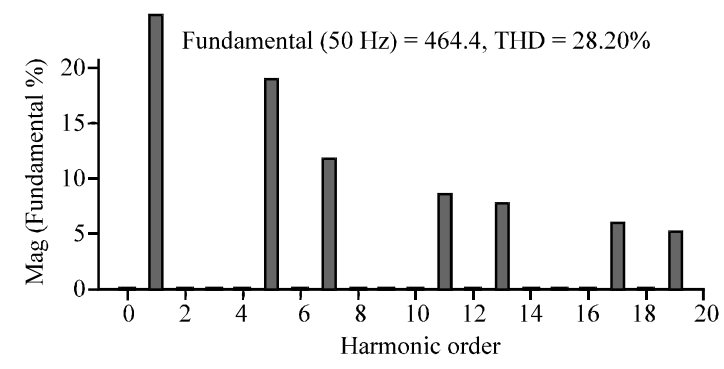

Fig. 6: THD and RMS values of voltage without PF for non-sinusoidal source and the THD of the voltage waveform has been improved from $21.52-7.42 \%$ using GA similarly for PSO the THD of the source current under such condition has been improved from $18.61-4.31 \% \mathrm{u}$ and the THD of the voltage waveform has been improved from $21.52-10.52 \%$.

Figure 9 and 11 shows the THD of the load and source currents and voltage at PCC using GA and PSO, the THDs of the source current and voltage at PCC dynamically improve when compare without passive filters. One very important aspect of the design corresponding to net reduction in RMS supply current

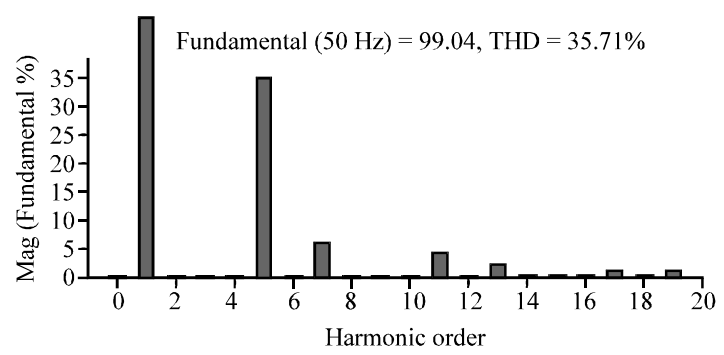

Fig. 7: THD and RMS values of current without PF for non-sinusoidal source

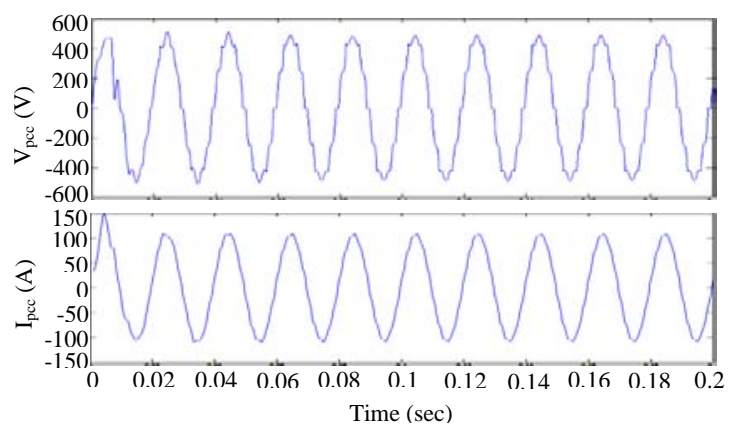

Fig. 8: Response of passive filters for VFDs for sinusoidal source GA
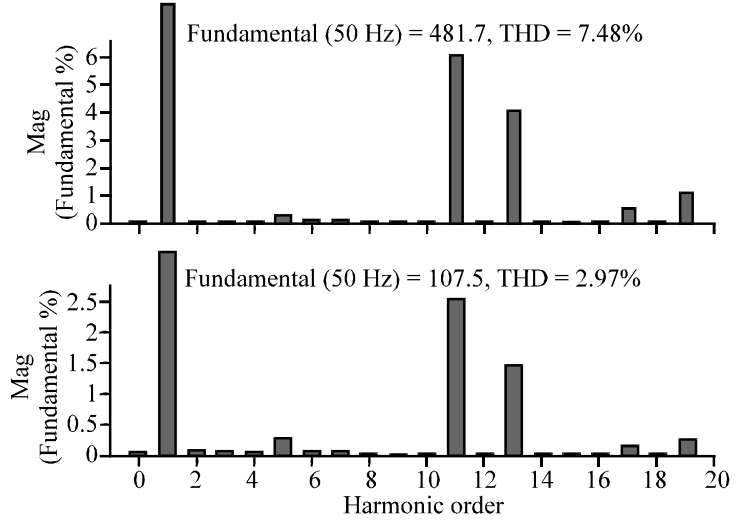

Fig. 9: THD and RMS values of voltage and current at PCC using GA 
Table 1: Percentage THD and RMS value of source current and voltage at PCC with and without passive filter using GA under undistorted mains

\begin{tabular}{lcr}
\hline Current/voltage & RMS values & THD\% \\
\hline Source current & 76.39 & 18.61 \\
Source current with CPF & 69.78 & 4.72 \\
Source current with DPF & 75.56 & 2.97 \\
Voltage at PCC & 318.90 & 21.52 \\
Voltage at PCC with CPF & 332.20 & 11.48 \\
Voltage at PCC with DPF & 340.40 & 7.42 \\
\hline
\end{tabular}

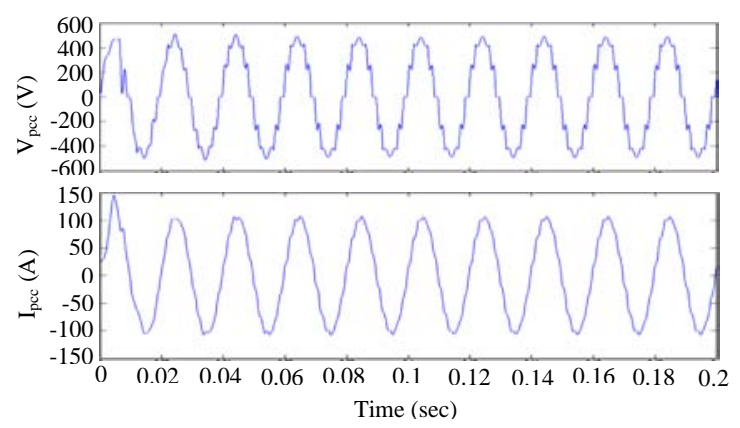

Fig. 10: Response of passive filters for VFDs for sinusoidal source using PSO
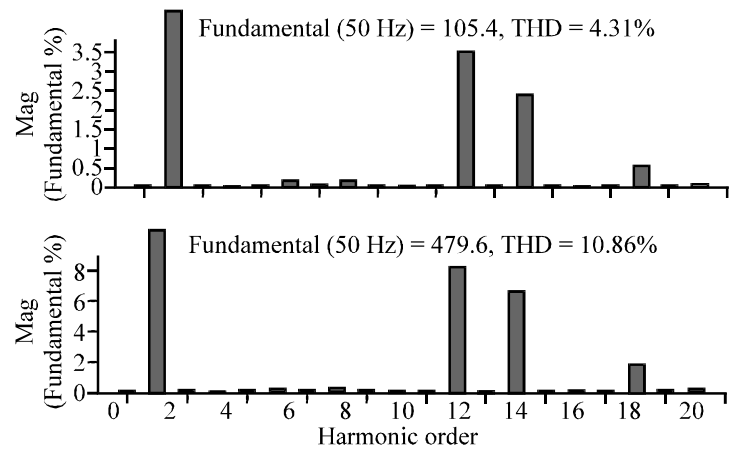

Fig. 11: THD and RMS values of voltage and current at $\mathrm{PCC}$ using $\mathrm{PSO}$

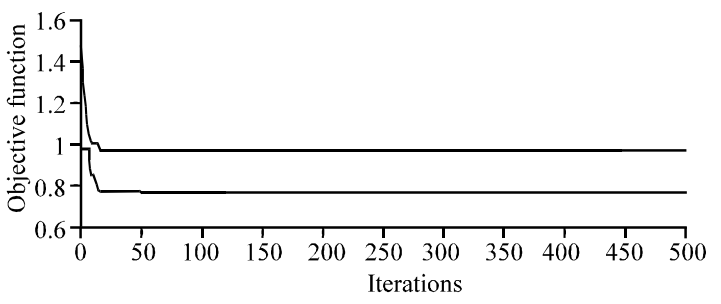

Fig. 12: Response of fitness function for GA and PSO

holds true for both types of placements of passive filters in the power system. Table 1-4 show about the \%THD and RMS values obtained by GA and PSO without passive filters with common passive filters and with distributed passive filters.

When compare to the values obtained through PSO are better than the GA. Figure 12 shows the response of
Table 2: Percentage THD and RMS value of source current and voltage at $\mathrm{PCC}$ with and without passive filter using GA under distorted mains

\begin{tabular}{lcr}
\hline Current/voltage & RMS values & THD\% \\
\hline Source current & 81.25 & 35.53 \\
Source current with CPF & 72.50 & 4.12 \\
Source current with DPF & 79.26 & 3.11 \\
Voltage at PCC & 325.35 & 29.33 \\
Voltage at PCC with CPF & 336.56 & 11.67 \\
Voltage at PCC with DPF & 345.45 & 8.53 \\
\hline
\end{tabular}

Table 3: Percentage THD and RMS value of source current and voltage at $\mathrm{PCC}$ with and without passive filter using PSO under undistorted mains

\begin{tabular}{lcr}
\hline Current/voltage & RMS values & THD\% \\
\hline Source current & 76.39 & 18.61 \\
Source current with CPF & 72.59 & 1.72 \\
Source current with DPF & 75.80 & 0.63 \\
Voltage at PCC & 318.90 & 21.52 \\
Voltage at PCC with CPF & 335.40 & 4.31 \\
Voltage at PCC with DPF & 3459.20 & 2.32 \\
\hline
\end{tabular}

Table 4: Percentage THD and RMS value of source current and voltage at PCC with and without passive filter using PSO under distorted mains

\begin{tabular}{|c|c|c|}
\hline Current/voltage & RMS values & $\mathrm{THD} \%$ \\
\hline Source current & 81.25 & 35.53 \\
\hline Source current with CPF & 73.58 & 3.84 \\
\hline Source current with DPF & 78.44 & 3.08 \\
\hline Voltage at $\mathrm{PCC}$ & 325.35 & 29.33 \\
\hline Voltage at $\mathrm{PCC}$ with $\mathrm{CPF}$ & 345.45 & 4.33 \\
\hline Voltage at PCC with DPF & 375.33 & 3.30 \\
\hline \multicolumn{3}{|c|}{ Table 5: Parameters of the considered system } \\
\hline Parameters & Values & \\
\hline Cable impedance & $0.8 \Omega \mathrm{km}^{-1}, 0.3$ & $\mu \mathrm{F} \mathrm{km}-$ \\
\hline Transformer equivalent & $0.1 \Omega, 5 \mathrm{mH}$ & \\
\hline \multirow[t]{3}{*}{ Load side impedance } & VSD1: $\mathrm{CL}=200$ & \\
\hline & VSD2: $\mathrm{CL}=200$ & \\
\hline & VSD3: $\mathrm{CL}=200$ & \\
\hline AC mains & $230 \mathrm{~V}, 50 \mathrm{~Hz}$ & \\
\hline \multirow[t]{4}{*}{ Filter parameters for $\mathrm{GA}$} & $\mathrm{C} 5=38.44 \mu \mathrm{F} ; \mathrm{I}$ & \\
\hline & $\mathrm{C} 7=38.44 \mu \mathrm{F} ; \mathrm{I}$ & \\
\hline & $\mathrm{C}_{\mathrm{HP}}=39.78 \mu \mathrm{F}$ & \\
\hline & $\mathrm{R}_{\mathrm{HP}}=3.5 \Omega$ & \\
\hline \multirow[t]{4}{*}{ Filter parameters for PSO } & $\mathrm{C} 5=36.84 \mu \mathrm{F} ; \mathrm{I}$ & \\
\hline & $\mathrm{C} 7=18.79 \mu \mathrm{F} ; \mathrm{I}$ & \\
\hline & $\mathrm{R}_{\mathrm{HP}}=27.01 \mu \mathrm{F} ; \mathrm{I}$ & \\
\hline & $\mathrm{R}_{\mathrm{HP}}=2.54 \Omega$ & \\
\hline
\end{tabular}

objective function for GA and PSO. The parameters of the considered system of the study are shown in Table 5.

\section{CONCLUSION}

This study has presented a new technique to design series tuned and 2 nd order band pass passive filters. The design has been emphasized for reduction of harmonic current together with minimization of RMS source current and reactive requirement. The observed performance, through analyzing the result has demonstrated the ability of the proposed designed passive filters to compensate the current harmonics effectively along with the reduction of the net RMS source current. The placement of the 
designed passive filter has been studied for two different places. It has been found that the DPF for each VFD reduces the THD of source current and voltage at PCC more than a CPF at the bus. Moreover, the DPFs which draw a little more current and slightly increase the voltage at PCC are recommended for safer operation because of increased overload capacity to work under series resonance carried by distorted mains which is prominent in petroleum industries.

\section{REFERENCES}

Berizzi, A. and C. Bovo, 2000. The use of genetic algorithms for the localization and the sizing of passive filters. Proc. Int. Conf. Harmon. Qual. Power, 1: 19-25.

Chen, Y.M., 2003. Passive filter design using genetic algorithms. IEEE Trans. Ind. Electron., 50: 202-207.

Chipperfield, A., P. Fleming, H. Pohlheim and C. Fonseca, 1994. Genetic Algorithm Toolbox for use with MATLAB. University of Sheffield, UK.

Das, J.C., 2004. Passive filters-Potentialities and limitations. IEEE Trans. Ind. Appl., 40: 232-241.

Goldberg, D.E., 1989. Genetic Algorithms in Search, Optimization, and Machine Learning. AddisonWesley, London, U.K..

Haozhong, C., H. Sasaki and N. Yorino, 1995. A new method for both harmonic voltage and harmonic current suppression and power factor correction in industrial power systems. Proceedings of the IEEE Industrial and Commercial Power Systems Technical Conference, May 7-12, 1995, USA., pp: 27-34.

IEEE, 2003. Guide for Application and Specification of Harmonic Filters, IEEE Std 1531-2003, 2003, 10.1109/IEEESTD. 2003.94407

Kawann, C. and A.E. Emanuel, 1996. Passive shunt harmonic filters for low and medium voltage: A cost comparison study. IEEE Trans. Power Syst., 11: 1825-1831.
Lin, K.P., M.H. Lin and T.P. Lin, 1998. An advanced computer code for single-tuned harmonic filter design. IEEE Trans. Ind. Appl., 34: 640-648.

Merhej, S.J. and B. Nichols, 1992. Harmonic filtering for the offshore industry. Proceedings of the Industry Applications Society 39th Annual Petroleum and Chemical Industry Conference, September 28-30, 1992, USA., 111-120.

Moura, C.C.M., M.E.L. Tostes, E.P. Santos, R.C.L. Oliveira, T.M.M. Branco and U.H. Bezerra, 2002. Determination of the R-L-C parameters of a passive harmonic filter using genetic algorithm. Proceedings of the IEEE 10th International Conference on Harmonics and Quality of Power, October 6-9, 2002, Brazil, pp: 495-500.

Nelson, J.P., 2004. A better understanding of harmonic distortion in the petrochemical industry. IEEE Trans. Ind. Appl., 40: 220-231.

Petro, D.W. and R.L. Wood, 1994. Power quality issues regarding adjustable speed drives in petroleum terminals. Proceedings of the IEEE Petroleum and Chemical Industry Conference, September 12-14, 1994, Canada, pp: 227-234.

Sarangi, S., 2009. Particle swarm optimization applied to economic load dispatch problem. M.Tech. Thesis, Department of Electrical Engineering, National Institute of Technology, Rourkela, India.

Upadhyaya, S.D. and Y.R. Atre, 1998. Determination of the design parameters of passive harmonic filters using non-linear optimization. Proceedings of the IEEE Industrial and Commercial Power Systems Technical Conference, May 3-8, 1998, Edmonton, Alta, pp: 155-164.

Verma, V. and B. Singh, 2010. Genetic-Algorithm based design of passive filters for offshore applications. IEEE Trans. Ind. Appl., 46: 1295-1303.

Wakileh, G.J., 2001. Power System Harmonics: Fundamentals, Analysis and Filter Design. SpringerVerlag, Berlin, Germany. 